\title{
Los héroes de la pandemia: la construcción discursiva del colectivo de los trabajadores sanitarios durante la crisis del COVID-19*
}

DOI: https://www.doi.org/10.18046/recs.i33.4057

The Heroes of the Pandemic: The Discursive Construction of the Healthcare Workers Collective during the COVID-19 Crisis

Sebastián Moreno-Barreneche ${ }^{* *}$

Universidad ORT Uruguay (Montevideo, Uruguay)

\footnotetext{
* El trabajo que dio como resultado este artículo se financió con recursos propios. Artículo de reflexión recibido el 05.06.2020 y aceptado el 16.11.2020.

** Profesor adjunto en la Facultad de Administración y Ciencias Sociales de la Universidad ORT Uruguay (Uruguay), donde tiene a su cargo los cursos "Cultura y sociedad contemporánea" y "Europa: entre unión y diversidad". Correo electrónico: morenobarreneche@gmail.com ORCID: https://orcid.org/0000-0003-3551-7117
} 


\section{Cómo citar/How to cite}

Moreno-Barreneche, Sebastián (2021). Los héroes de la pandemia: la construcción discursiva del colectivo de los trabajadores sanitarios durante la crisis del COVID-19. Revista CS, 33, 75-101. https://www.doi.org/10.18046/recs.i33.4057 


\section{Resumen}

Más allá de su impacto en los dominios de la salud, la economía y la política, la pandemia asociada al COVID-19 ha dado lugar a fenómenos de naturaleza discursiva, particularmente en cuanto a los modos en que las sociedades han atribuido sentido a la crisis originada por la propagación descontrolada del virus. A partir de un enfoque sociosemiótico, en este artículo se analiza el proceso de construcción de la identidad colectiva de los trabajadores sanitarios durante la pandemia. Luego de presentar de manera general a la semiótica como la disciplina interesada por el sentido y la significación, se examinan cuatro mecanismos semióticos identificables en los procesos de construcción discursiva de las identidades colectivas, con el fin de estudiar cómo estos se han manifestado durante la pandemia, en el caso específico de los trabajadores sanitarios. Como se demuestra, el caso permite visualizar de manera clara los mecanismos semióticos de segmentación, actorialización, generalización y axiologización.

PALABRAS CLAVE:

coronavirus, COVID-19, trabajadores sanitarios, semiótica, constructivismo

Besides its impact in health, economics, and politics, the COVID-19 pandemic has allowed the emergence of phenomena of discursive nature, specifically regarding the solutions societies have found to make sense of the crisis caused by the uncontrolled spread of the virus. From a socio-semiotic approach, this article analyzes the collective identity construction process of the healthcare workers during the pandemic. After generally introducing semiotics as the discipline interested in meaning-making and signification, this paper studies four semiotic mechanisms that can be identified in the processes of discursive construction of collective identities. The aim is to explore how those have been developed during the pandemic in the specific case of healthcare workers. As it is shown, the case renders visible the semiotic mechanisms of segmentation, actorialization, generalization, and axiologization.

\section{KEYWORDS:}

Coronavirus, COVID-19, Healthcare Workers, Semiotics, Constructivism 



\section{Introducción}

En enero de 2020, un virus, hasta ese momento desconocido por la comunidad científica, se volvió noticia a nivel global debido a su rápida propagación. Inicialmente considerado como un problema de China, específicamente de la provincia de Huabei y la ciudad de Wuhan, luego de las primeras infecciones en Italia, en febrero del mismo año, la amenaza se volvió más real para el mundo occidental, en primer lugar, para Europa y, luego, para las Américas. De este modo, el novel coronavirus, conocido coloquial y simplemente como coronavirus, causante de la enfermedad COVID-19 y de los períodos de confinamiento más importantes de la historia reciente, pasó a estar en el centro de atención de medios de comunicación, gobiernos, académicos y vecinos, no solamente por sus peligrosos efectos en la salud humana, sino también por las catastróficas consecuencias económicas asociadas a las medidas tomadas por los gobiernos para contener su propagación y, con ella, el colapso de los sistemas nacionales de salud. El año 2020 ha sido, sin lugar a dudas, el año del coronavirus.

Más allá de los efectos que produjo en la salud, la economía y la política, la pandemia del COVID-19 también ha dado lugar a una serie de fenómenos de naturaleza discursiva, particularmente en cuanto a los modos en que las distintas sociedades han atribuido sentido a esta crisis. Estos fenómenos son de profundo interés para quienes se interesan por los estudios del discurso y por la semiótica, disciplina cuyo objeto está constituido por los procesos de significación y circulación de sentido en el seno de la vida social. Por mencionar algunos ejemplos, un fenómeno de sumo interés ha sido el de la construcción del coronavirus como un enemigo, en algunos casos hasta con rasgos antropomórficos -una cara, gestualidad, intencionalidad-, con quien la humanidad está en guerra (Moreno-Barreneche, 2020a). En este sentido, si bien el coronavirus existe como una entidad biológica, su propagación ha sido acompañada por una serie de procesos de producción textual en los que esta entidad, invisible al ojo humano, ha sido transformada en algo con sentido para las sociedades a lo largo y ancho del mundo.

Otro de los fenómenos de naturaleza discursiva asociados a la pandemia del COVID-19 estuvo relacionado con la construcción y el empleo, a nivel discursivo, de ciertas narrativas e imaginarios vinculados con una serie de actores colectivos involucrados, de alguna manera, en la trama de la pandemia, especialmente en lo que refiere al procesos de atribución de culpa dentro del marco más amplio de atribución de sentido a una situación inédita que se presentó como una amenaza a la normalidad y al status quo (Moreno-Barreneche, 2020b). Así, en primer lugar, la categoría de sentido los chinos fue empleada como forma de atribuir responsabili- 
dad a una cultura en su totalidad por la propagación del virus. ${ }^{1}$ Posteriormente, con la pandemia ya expandida y con las medidas de confinamiento tomadas en varios países, comenzó a haber referencias al grupo de los irresponsables, que renegaban de la pandemia y no acataban las medidas o recomendaciones de los gobiernos de sus países de residencia, alcanzando su punto máximo en los jóvenes estadounidenses no dispuestos a dejar de lado la fiesta con el argumento de que si "me infecto de corona, me infecto de corona" (Noor, 2020).

Finalmente, dependiendo del país y de la región, otros colectivos también han sido utilizados a nivel discursivo como chivos expiatorios, tanto por medios de comunicación como por políticos y hasta por la ciudadanía, a la hora de atribuir sentido (quizá aquí la expresión inglesa "to make sense" sea más apropiada para explicar este mecanismo) a la crisis que el mundo ha vivido durante el 2020. En el caso del Cono Sur de América Latina, rápidamente surgió la narrativa que atribuía a los chetos -una forma despectiva de referirse a las clases más acomodadas de la sociedad- la responsabilidad de introducir el virus en países como Argentina y Uruguay, dado que son ellos quienes tenían la posibilidad de viajar a Europa y, a su regreso, llevar la enfermedad a sus países de origen (Abdala, 2020).

Como se puede apreciar, asociada a la crisis sanitaria causada por el COVID-19 ha habido también una serie de fenómenos discursivos interesantes, especialmente vinculados con la construcción de roles específicos que permitieron articular una narrativa para atribuir sentido a la crisis: un enemigo a quien derrotar, alguien a quien culpar por la pandemia (ya que, por no ser un agente moral, la naturaleza no puede ser culpada), una víctima (la humanidad) que debe realizar un sacrificio al dejar de lado la vida normal y las relaciones sociales. En este contexto general, de carácter inherentemente semiótico, otro de los actores colectivos construidos discursivamente a partir de ciertas imágenes, narrativas, testimonios, imaginarios y demás mecanismos significantes ha sido el de los trabajadores sanitarios (o trabajadores de la salud). Como tal, esta identidad colectiva abarca a médicos, enfermeros, paramédicos, camilleros, conductores de ambulancias, entre tantos otros roles sociales pertenecientes al ámbito profesional de la salud y, por ello, ya conocidos por la gente común y corriente. Durante la pandemia, estos roles, además de claramente identificados bajo la forma de un colectivo con identidad propia, han sido valorizados positivamente como los "héroes sin capa" (El personal sanitario, 2020; Lesser, 2020; Organización de las Naciones Unidas [ONU], 2O2O), en un relato donde el enemigo es un agente natural al que, recurriendo a la metáfora de la guerra

1. Es pertinente recordar en este punto la foto del discurso impreso de Donald Trump en la que se ve cómo, para referirse al virus, manualmente cambió el prefijo corona, impreso en el texto original, por Chinese, para aludir directamente a su procedencia china. 
que ha sido hegemónica durante la pandemia, hay que combatir en la "primera línea de batalla" (Heroes, 2020; Los sanitarios en primera línea, 2020).

Desde un marco teórico semiótico-específicamente sociosemiótico-, este artículo tiene por objetivo reflexionar acerca de los mecanismos a partir de los cuales la identidad colectiva de los trabajadores sanitarios o de la salud (healthcare workers, en inglés) ha sido construida discursivamente en el contexto de la pandemia del COVID-19. Con esta finalidad, en la primera sección del texto se presenta, de manera breve y general, a la semiótica a partir de algunas de sus ideas centrales, como forma de orientar a los lectores que no estén familiarizados con la disciplina. Luego, en una segunda sección, se presenta una conceptualización acerca de la construcción discursiva de identidades colectivas a partir de una serie de procedimientos semióticos; estos son: la segmentación, la actorialización, la generalización y la axiologización. Finalmente, en la tercera y última sección, se estudia el caso concreto de la construcción discursiva de la identidad colectiva trabajadores sanitarios.

\section{La semiótica y la cuestión del sentido en la esfera social}

Si bien la semiótica es una disciplina rastreable ya en la Antigüedad (Manetti, 2013), logra consolidarse como un campo de investigación relativamente autónomo en el siglo XX, a partir de una fuerte relación con la lingüística y la filosofía del lenguaje. De hecho, se suele referir al lingüista suizo Ferdinand de Saussure como uno de los padres fundadores de la disciplina, ya que fue él quien, en su Curso de lingüistica general, publicado en 1916, describió a la semiótica como una ciencia aún por desarrollarse y que formaría parte de la psicología social, avocada al estudio de los signos en el seno de la vida social. Por otra parte, el trabajo del filósofo americano Charles S. Peirce, interesado en una dimensión más bien epistemológica y no tanto centrada en el lenguaje, ayudó a consolidar a la semiótica como un campo de investigación relevante, particularmente en la segunda mitad del siglo $\mathrm{XX}$, dando lugar a dos corrientes bien demarcadas dentro de la disciplina, que hoy en día se conocen con los nombres de semiótica estructural, más apoyada en el lenguaje y la lingüística, y semiótica interpretativa, más interesada por los procesos cognitivos y fuertemente ligada a la filosofía del lenguaje, de la mente y del conocimiento (Traini, 2006; Violi, 2017). A partir de esta distinción general, según la tradición con la que el investigador se identifique, se aceptará una definición de la disciplina y, con ella, los conceptos, modelos, y herramientas teóricas y analíticas que se emplearán en la investigación.

Tanto Saussure como Peirce centraron su trabajo en el estudio de los signos como unidades de análisis, lo que ha dado lugar a que, durante décadas, la semiótica fuera considerada de manera simplista como una ciencia de los signos, de carácter 
esencialmente descriptivo. Sin embargo, a partir de una ampliación teórico-metodológica durante las últimas décadas, resultante de la búsqueda de autonomía y especificidad por parte de la disciplina, hoy en día su objeto de estudio se define ya no a partir del análisis de signos y conjuntos de ellos (textos strictu sensu), sino a partir de los múltiples, heterogéneos y complejos procesos de producción de sentido y significación que ocurren dentro de la esfera sociocultural (Hénault, 2012; Marrone, 2018; Verón, 1989). Como afirma el semiólogo argentino Eliseo Verón (1988: 125), "todo fenómeno social es, en una de sus dimensiones constitutivas, un proceso de producción de sentido". Este enfoque incluye dentro del campo de interés de la semiótica no solamente el estudio de corpus textuales claramente delimitados y empíricamente accesibles (piezas audiovisuales, literatura, propaganda política, etc.), sino también dimensiones de corte más existencial (Fontanille, 2015; Landowski, 2012). De hecho, para el semiólogo francés Eric Landowski (2012: 129), el objetivo de la semiótica consiste en "comprender mejor cómo, en qué condiciones, por qué procedimientos nuestra presencia en el mundo llega a tener sentido". Es así que, desde una perspectiva más orientada a la construcción disciplinar, el también francés Jean-Marie Floch (1990: 22) afirma que "la semiótica se define por el campo de investigación que le pertenece: los lenguajes -todos los lenguajes-y las prácticas significantes, que son esencialmente prácticas sociales”, por lo que, según el autor, "su objetivo es la descripción de las condiciones de producción y de comprensión del sentido" (Floch, 1990: 23).

La premisa subyacente a la semiótica es de carácter constructivista: la realidad social es en gran parte construida a partir de procesos intersubjetivos de significación y de negociación de sentido (Verón, 1988). Desde un enfoque con estas características, con una clara influencia del estructuralismo dominante a mediados del siglo $\mathrm{XX}$, se intenta superar los enfoques realistas, positivistas y materialistas, ya que lo que interesa es estudiar el sentido en acción a partir de las múltiples y heterogéneas dinámicas de producción de significado que caracterizan la vida cotidiana. En sus estudios etnográficos, el antropólogo Clifford Geertz (1973: 20) planteaba, apoyándose en el trabajo de Max Weber, una concepción semiótica de la cultura según la cual "el hombre es un animal inserto en tramas de significación que él mismo ha tejido", por lo que la cultura sería un sistema caracterizado por procesos complejos de producción, distribución y consumo de sentido, cuyo estudio, más que un enfoque cuantitativo y mecanicista, ameritaría un trabajo de semántica social, esto es, de interpretación de las prácticas culturales de un grupo dado como si fueran textos para aprehender su sentido y el significado que estas tienen para quienes las llevan a cabo.

La concepción de la cultura que maneja Geertz tiene varios puntos en común con el planteo que Umberto Eco (1976) hace en el Tratado de semiótica general, obra clave 
de la semiótica debido a su intento de establecer una síntesis entre las dos grandes tradiciones históricas dentro del campo. En su libro, Eco (1976: 44) equipara una teoría semiótica general con una teoría general de la cultura, ya que, según el autor, "humanidad y sociedad existen solo cuando se establecen relaciones de significación y procesos de comunicación", lo que lo lleva a afirmar que "la cultura por entero debería estudiarse como un fenómeno de comunicación basado en sistemas de significación" (Eco, 1976: 44-45).

Dentro de este encuadre general, la sociosemiótica se concibe como una rama específica de la semiótica general a partir de su foco de interés: los fenómenos sociales, principalmente en la forma de prácticas (Demuru, 2017; Dondero, 2017; Floch, 1990; Fontanille, 2008) y de interacciones (Landowski, 1997; 2016a). Esta rama de la semiótica se desarrolla a partir de la década de 1970, principalmente en Francia, América Latina e Italia. Para Landowski (2014: 10-11), uno de sus principales representantes, la consolidación del área de investigación ocurrió "bajo la forma de un número continuamente creciente de investigaciones sobre dominios tan variados, que su enumeración puede parecer heteróclita", como pueden ser los medios de comunicación, los discursos sociales, las prácticas políticas, los espacios y las relaciones entre sujetos y objetos. En palabras del autor,

poco importa que se trate de textos o de prácticas (de "mitos" o de "ritos"), de obras artísticas o de productos de la industria, de comportamientos individuales o de usos colectivos, de normas o de instituciones, siempre que presenten un carácter observable, articulado y, por lo tanto, significante. (Landowski, 2016b: 14)

Se trata entonces de aprehender "la vida cotidiana en sus múltiples dimensiones" mientras esta se desarrolla, es decir, in vivo (Landowski, 2014: 10). De este modo, actualmente la semiótica se interesa cada vez más por estudiar la memoria colectiva (Demaria, 2006; Violi, 2014), el conflicto (Mazzucchelli, 2010), el espacio (Giannitrapani, 2013; Marrone, 2013), las interacciones (Landowski, 2016a) y la alteridad (Landowski, 1997), entre tantos otros fenómenos, por lo general tradicionalmente concebidos como naturales, dados o presociales, desde otra óptica: la asunción es que se trata de construcciones socioculturales desarrolladas a partir de fenómenos discursivos y de circulación de sentido apoyados en redes intersubjetivas de significación. Es así que Eliseo Verón, que sin dudas es uno de los referentes más visibles de la disciplina, especialmente en lo que concierne al discurso político (Verón, 1987; 1989) y al fenómeno de la mediatización (Verón, 1994; 1997; 1998), afirma que "la mirada semiótica es una mirada intersticial, que persigue la reconstrucción de la producción del sentido en el seno de las redes interdiscursivas de nuestras sociedades" (Verón, 1989: 138). 
En síntesis, hoy en día la sociosemiótica se concibe a sí misma como en una íntima relación con la antropología y la sociología, dado que su objeto de estudio se solapa con el de estas disciplinas, aunque su foco está centrado específicamente en el sentido y la significación como objeto de estudio. Durante las últimas décadas, a partir de la influencia del constructivismo en las ciencias sociales, los puentes entre las disciplinas se han fortalecido, dando lugar a que cada una tenga algo específico que aportar en el análisis de la complejidad de la realidad sociocultural.

\section{Una aproximación semiótica a la construcción discursiva de las identidades colectivas}

Luego de presentar, en términos generales, a la semiótica como disciplina interesada por el sentido y la significación, esta sección se centrará en discutir algunos mecanismos semióticos asociados a la construcción de identidades colectivas en términos discursivos. Si la sociosemiótica se interesa por la atribución de sentido en las prácticas intersubjetivas cotidianas, entonces comprender de qué manera la percepción de la realidad se articula a partir de determinadas categorías de sentido se vuelve un objeto de claro interés para la disciplina.

La premisa subyacente a lo que se presenta a continuación se apoya en una de las ideas básicas de la denominada semiótica cognitiva: aquella según la cual la percepción por parte de los individuos del mundo, tanto exterior como interior, se articula en términos narrativos, a partir de un principio de narratividad, ya que "la narratividad es la forma del sentido" (Paolucci, 2012: 303). Esta idea ha sido desarrollada en paralelo tanto en el marco de la semiótica como de las ciencias cognitivas (Paolucci, 2012), por lo que la semiótica cognitiva intenta articular ambos campos a partir de la hipótesis según la cual la experiencia percibida es ordenada con base en los mecanismos asociados a la creación de historias, incluyendo la creación de actores con ciertos roles en la trama que es imaginada. Se trata, en palabras de Claudio Paolucci (2012: 300), de comprender "cómo la narratividad es susceptible de influenciar, modular y transformar la manera en que pensamos la cognición”. Como propone el autor, los desarrollos más actuales en ciencias cognitivas se acercan cada vez más a aquellos de la semiótica.

Por ser una disciplina constructivista, una de las premisas centrales de la semiótica es su antiesencialismo, es decir, que el significado no es algo dado, sino que surge a partir del establecimiento de diferencias (Eco, 1976; Hjelmslev, 1943; Violi, 2017). En términos lingüísticos, esto significa que una palabra tiene sentido para una cultura a partir de una oposición a otros términos que se diferencian de 
ella. En términos socioculturales, esta premisa se traduce en la necesidad de una construcción discursiva de identidades colectivas a partir del establecimiento de ciertas fronteras entre actores sociales que son imaginados como diferentes a partir de ciertos procesos de carácter semiótico (Moreno-Barreneche, 2020d).

Como toda distinción entre conceptos, también en el campo social el establecimiento de este tipo de fronteras es arbitrario, esto es, no tiene nada de natural o dado. Como argumentan los politólogos Chantal Mouffe (2007) y Ernesto Laclau (2005), en sus estudios sobre el discurso político -con un importante componente semiótico, por cierto-, este tiene una inescapable dimensión antagónica, consistente en un conflicto entre identidades colectivas, construidas sobre la base de una dicotomía entre un nosotros y un ellos. De manera similar, Verón (1987) sostiene que la política es aquel campo discursivo donde se gestionan a largo plazo las identidades colectivas. Según el autor, este se caracteriza por una dialéctica de enfrentamiento.

El mecanismo de construcción discursiva (e imaginaria) de identidades colectivas no es exclusivo de la política, sino que puede apreciarse también en la vida cotidiana, a partir de la construcción de actores colectivos cuya existencia ayuda a ordenar en términos narrativos el mundo percibido. A modo de ejemplo, se habla de (o piensa en) los políticos como una categoría de sentido general, homogénea y claramente delimitada como actriz clave a la hora de atribuir sentido a ciertos fenómenos sociales, como, por ejemplo, mediante la atribución de una relación causa-efecto a partir de la creencia de que los políticos-todos ellos-son corruptos o mienten. Lo mismo sucede con tantas otras categorías de sentido asociadas a identidades colectivas, muchas de ellas extremadamente problemáticas no solo en cuanto a su segmentación, sino también en cuanto a su valorización en términos discursivos, como ser los extranjeros o los inmigrantes, entre otras (Bauman, 2016; Moreno-Barreneche, 2020c).

¿Cómo es que se construyen, en términos discursivos, las categorías de sentido asociadas a identidades colectivas que son empleadas para dar sentido a la realidad social, en términos narrativos? En lo que sigue, se discutirán cuatro mecanismos de naturaleza semiótica, que luego nos permitirán analizar el objeto de estudio concreto que interesa en este artículo. Estos son: la segmentación, la actorialización, la generalización y la axiologización. Si bien se presentarán de manera sucesiva, todos estos mecanismos son sincrónicos, volviendo a la construcción discursiva de identidades colectivas un fenómeno complejo en el que las diferentes dimensiones se interrelacionan y retroalimentan permanentemente.

El primer mecanismo es el de la segmentación, es decir, la delimitación de un área de sentido (campo semántico) que se considera diferente de otras y que conduce a la identificación de la identidad colectiva en cuestión como única. Este mecanismo se apoya en la premisa estructural de la semiótica según la cual el significado y el 
sentido no son algo dado, sino que surgen a partir de juegos de oposiciones, esto es, de manera relacional. Como propone Patrizia Violi (2017: 27), "los elementos singulares no tienen un valor en sí mismos, absoluto, ontológico, definido esencialmente de una vez y para siempre, sino que adquieren valor y sentido solo a partir del confrontarse con lo que no son; esto es, solo en el valor posicional de la relación con un otro". Esta premisa antiesencialista es también compartida por quienes se han interesado por la construcción de identidades en el terreno político (Laclau; Mouffe, 1985; Mouffe, 2007).

Al segmentar el continuum de todas las identidades colectivas posibles, el hecho de identificar a una en particular como distinta de otras implica un proceso arbitrario de segmentación, siguiendo una lógica ya identificada por el lingüista danés Louis Hjemlslev (1943) y sistematizada luego en términos semióticos por Umberto Eco en el Tratado de semiótica general. Allí, Eco (1976:111) afirma que "el significado de un término (y, por lo tanto, el objeto que el término 'denota') es una unidad cultural", por lo que "cualquier intento de establecer el referente de un signo nos lleva a definirlo en los términos de una entidad abstracta que representa una convención cultural". El significado de un término, incluyendo también categorías más generales de sentido como los políticos, los jóvenes o los extranjeros, debe ser buscado a partir de las diferencias que se establecen entre el concepto en cuestión y otros, que son considerados como distintos por una comunidad lingüística dada. Así, para Eco (1976:121), una unidad cultural “'existe' solo en la medida en que se define otra por oposición a ella", una premisa que se ve claramente en un cuadro tomado del trabajo de Hjelmslev en el que el lingüista compara la manera diferente en que se establecen fronteras entre conceptos en danés, alemán y francés (Figura 1).

FIGURA 1 $\quad$ El significado como unidad cultural

\begin{tabular}{|c|c|c|}
\hline \multirow{2}{*}{ trae } & Baum & arbre \\
\hline & \multirow[t]{2}{*}{ Holz } & bois \\
\hline \multirow[t]{3}{*}{ skov } & & \\
\hline & \multirow{2}{*}{ Wald } & \\
\hline & & forêt \\
\hline
\end{tabular}


Como se puede apreciar en el cuadro, el significado, entendido como una unidad cultural de sentido que se define no por su referencia, sino por su oposición a otros conceptos, varía de cultura en cultura (en este ejemplo, cultura lingüística). En palabras de Eco (1976: 112),

en todas las culturas una unidad cultural es simplemente algo que esa cultura ha definido como unidad distinta de otras y, por lo tanto, puede ser una persona, una localidad geográfica, una cosa, un sentimiento, una esperanza, una idea, una alucinación.

Al estudiar la formación discursiva de identidades colectivas en el marco de una comunidad dada, el hecho de identificar una unidad de sentido como distinta de otras refleja la dinámica de este mecanismo de segmentación conceptual, en términos relacionales (Arfuch, 2005). En la próxima sección veremos cómo este mecanismo se aplica al caso concreto de los trabajadores sanitarios.

Una vez llevada a cabo la segmentación, comienza un proceso de actorialización, consistente en la construcción de la identidad segmentada en términos narrativos, discursivos y audiovisuales. Como se ha argumentado desde la semiótica, todo discurso social se organiza en términos narrativos a partir de relaciones entre diferentes actores, que cumplen funciones específicas en el relato. Así, luego de segmentado el continuum de las identidades posibles en unidades diferenciadas, es necesario materializar de algún modo estas unidades para volverlas tangibles y reconocibles empíricamente. En términos semióticos, se las debe figurativizar. Esto sucede a partir de diversos mecanismos de semiosis, cuando un contenido específico es asociado a determinadas unidades de expresión, como nombres, imágenes, descripciones, historias, identidades gráficas (logotipos, colores) o tantos otros recursos semióticos. Este mecanismo es claramente visible en la construcción, a modo de ejemplo, de partidos o grupos políticos: una vez identificados los límites (borrosos, claro) del grupo a partir de la adhesión a ciertas ideas y programas, todo un sistema de mecanismos semióticos es construido para volver tangible y reconocible la identidad del grupo: un nombre, un logotipo, banderas, afiches, determinados colores, campañas publicitarias, jingles, etc. El resultado es que el actor colectivo, cuya unidad es puramente imaginada, se vuelve más tangible como resultado de un proceso de semiosis en el que se establece una relación entre una unidad del plano del contenido y una (o más) del plano de la expresión.

En paralelo a la actorialización, las identidades colectivas suelen experimentar un proceso de generalización, a partir del cual se atribuyen ciertas características comunes, consideradas como esenciales de esa identidad, a todos los individuos que se imaginan como pertenecientes a la identidad colectiva en cuestión. En política, 
fórmulas del tipo los simpatizantes de la izquierda son así y los simpatizantes de la derecha son así son frecuentes, dejando poco margen para la diversidad interna, que sin dudas ocurre. En términos sociales, las generalizaciones del tipo los políticos son así y los extranjeros son así también son frecuentes.

Dado que, como se argumentó antes, las unidades de sentido asociadas a actores sociales colectivos no son referenciales - esto es, no tienen una denotación concreta por fuera del discurso-, los actores colectivos se constituyen y consolidan con base en esta caracterización general e imaginaria, a partir de la aplicación al colectivo de ciertos atributos genéricos (Appiah, 2018), que se imaginan como aplicables también a los integrantes del mismo. Claramente, en este proceso hay una tendencia a la simplificación que es extremadamente peligrosa en términos sociopolíticos, pero que, sin embargo, ocurre, con un impacto importante en cómo se imaginan y conciben las identidades colectivas. Quizá el ejemplo más visible de este mecanismo pueda ser la identidad colectiva el pueblo, particularmente como es empleada en el discurso populista (Laclau, 2005; Moreno-Barreneche, 2019). Como afirma Verón (1988: 128), "un discurso social, cualquiera que fuere su naturaleza o tipo, no refleja nada; él es sólo punto de pasaje del sentido".

Una vez identificada y segmentada la identidad colectiva, al mismo tiempo que es construida actorialmente y que algunos de sus atributos considerados como esenciales son postulados y aplicados de manera genérica a todos los miembros de la identidad, ocurre el que quizá sea el mecanismo más interesante desde una perspectiva sociosemiótica, así como el más peligroso: la axiologización o valorización. En términos semióticos, la axiologización puede ser definida siguiendo a Anne Hénault (2012: 275) como "la valorización estática de un universo de discurso dado", lo que refiere directamente a la atribución de valor a unidades de sentido a partir de ciertos sistemas de valores subyacentes. Como afirman Greimas y Courtés (1979), toda categoría semántica puede ser axiologizada a partir de una investidura de valores positivos y negativos según una dimensión pasional (tímica, en términos semióticos), que se articula como un eje lineal que oscila entre lo eufórico (lo valorado positivamente) y lo disfórico (lo valorado negativamente). La atribución de valor toma forma, principalmente, bajo la atribución de marcas connotativas -positivas y negativas- a los diferentes actores involucrados en la narrativa. En este proceso, las categorías semánticas asociadas a las identidades colectivas se ven investidas de cargas morales e ideológicas. Según Mouffe (2007: 12-13), esta moralización es una de las características más visibles de lo político en la época contemporánea: "el nosotros/ellos, en lugar de ser definido mediante categorías políticas, se establece ahora en términos morales", es decir, en la forma de una lucha imaginaria entre el bien y el mal, unidades de sentido contingentes, socialmente construidas a través 
de la historia, con fuertes cargas ideológicas, que resultan absurdas para captar de manera adecuada la complejidad de la realidad social.

Los cuatro mecanismos semióticos presentados en esta sección -segmentación, actorialización, generalización y axiologización- están en la base misma de la creación discursiva de las identidades colectivas, que son percibidas y articuladas en narrativas y discursos como aquellas que participan en y que llevan adelante la trama de lo social (la cual también se articula en términos narrativos). En la próxima sección se estudiará cómo estos mecanismos se han desarrollado en la construcción discursiva del actor colectivo trabajadores sanitarios en el contexto de la pandemia del COVID-19.

\section{La construcción discursiva del actor colectivo trabajadores sanitarios}

Antes de proceder al estudio que aquí interesa, es fundamental señalar un principio central de la sociosemiótica, íntimamente relacionado con un debate todavía actual dentro de la semiótica en general: aquel respecto a si el foco de estudio debe ponerse en las estructuras o en los procesos. Dijimos antes que una de las premisas de la semiótica, y en particular de su rama socio, es que la realidad social no tiene una esencia dada o presocial, sino que es el resultado de procesos intersubjetivos de construcción y reproducción a partir de la negociación del sentido entre actores sociales. Es así que, particularmente en la tradición francesa posgremiasiana, el sentido comenzó a ser asociado con el concepto de interacción, lo que ha llevado a que, como resultado, la sociosemiótica no se interese por describir sistemas de significación, sino por analizar los procesos a partir de los cuales el sentido emerge (Landowski, 2014; Verón, 1988). Por esta razón, el foco de lo que sigue estará puesto primariamente en el proceso de construcción de la identidad colectiva de los trabajadores sanitarios durante la pandemia.

Como todo trabajo semiótico implica lidiar con un corpus de materiales empíricos que permitan postular los principios subyacentes a la posibilidad de significación, estudiar la construcción discursiva del colectivo de los trabajadores sanitarios requiere reunir ciertos materiales de distinta naturaleza, y será a partir de ellos que se podrá estudiar cómo es que el sentido surge. Sin embargo, a diferencia de lo que sucede con corpus compuestos por textos más o menos cerrados y autónomos, el proceso que aquí interesa es uno abierto e in vivo, que no puede limitarse a una única materia, sino que se encuentra en expresiones de distinto tipo, que van desde representaciones desde afuera, como las que pueden hacer medios de prensa, actores 
políticos o artistas, hasta las que vienen desde dentro del colectivo, como pueden ser declaraciones en su nombre, videos de agradecimiento o prácticas de protesta. Por lo tanto, conformar un corpus para estudiar lo que aquí interesa es una tarea compleja.

Sin embargo, para realizar una segmentación mínima, en lo que sigue se considerarán cuatro manifestaciones de sentido: la creación de representaciones visuales del colectivo (Figuras 2, 3 y 4), las rondas de aplausos en agradecimiento a su labor (Figura 5), algunos textos periodísticos genéricos e ilustrativos tomados de medios de prensa (El personal sanitario, 202O; Heroes, 2020; Lesser, 202O; Los sanitarios en primera línea, 2020; ONU, 2020;) y, finalmente, acciones llevadas a cabo por individuos que se identifican con el colectivo en cuestión (Hospital staff, 2O2O). Se trata de un corpus heterogéneo, compuesto por imágenes, textos y prácticas.

Este corpus heteróclito, compuesto por distintos tipos de textos (en sentido amplio) a los que seguramente el lector podrá agregar innumerables otros, permite visualizar claramente ciertos mecanismos que pueden postularse como subyacentes a la construcción del actor colectivo que aquí interesa. Sin ir más lejos, en las Figuras 3, 4 y 5 destaca la referencia al contenido cultural de lo (súper)heroico; en el primer caso, figurativizado a partir de un gesto asociado a los superhéroes (abrir la camisa para develar su identidad heroica); en el segundo, con una yuxtaposición que identifica los cuerpos de los superhéroes con los de los trabajadores sanitarios; y, en el tercero, mediante el uso de la palabra héroes ("helden" / héros"). El hecho de

FIGURA 2 Mural en homenaje a los trabajadores sanitarios en Lisboa, Portugal

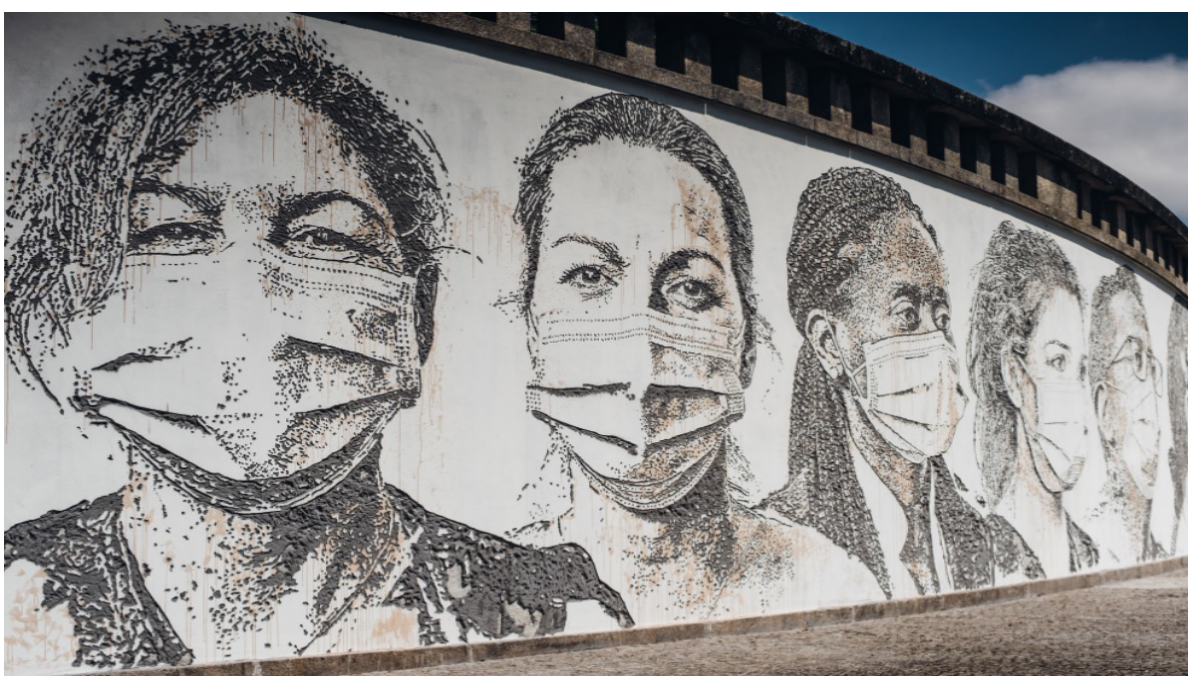


FIGURA 3 Mural en homenaje a los trabajadores sanitarios en Bruselas, Bélgica

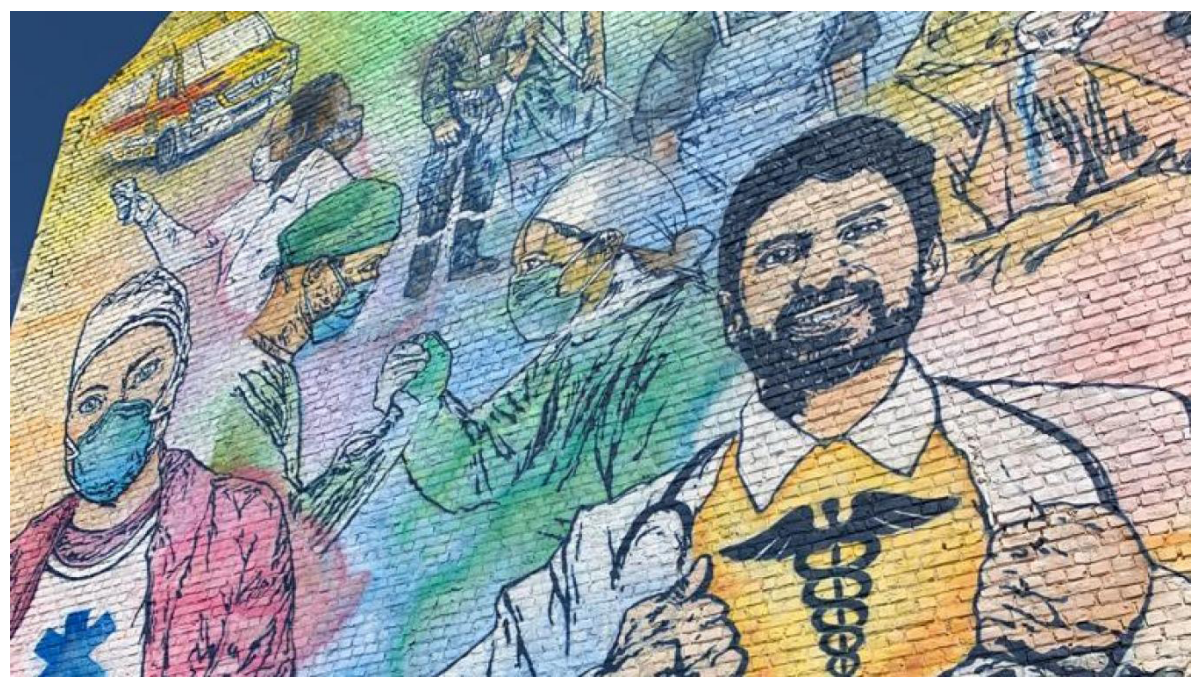

Fuente: Belga (2020).

FIGURA 4 Mural en homenaje a los trabajadores sanitarios en Sint-MartensLennik, Bélgica

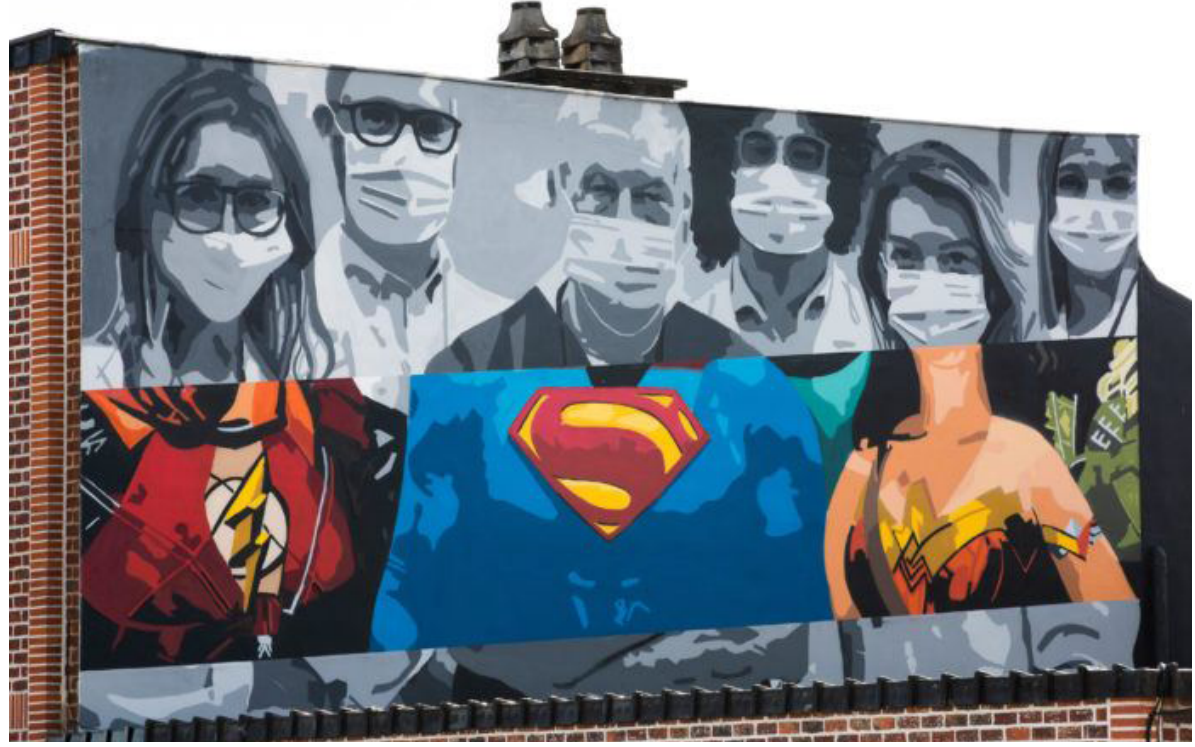


\begin{tabular}{l|l} 
FIGURA 5 & Convocatoria para aplaudir a los trabajadores de la salud que circuló
\end{tabular} en marzo de 2020 en Bélgica

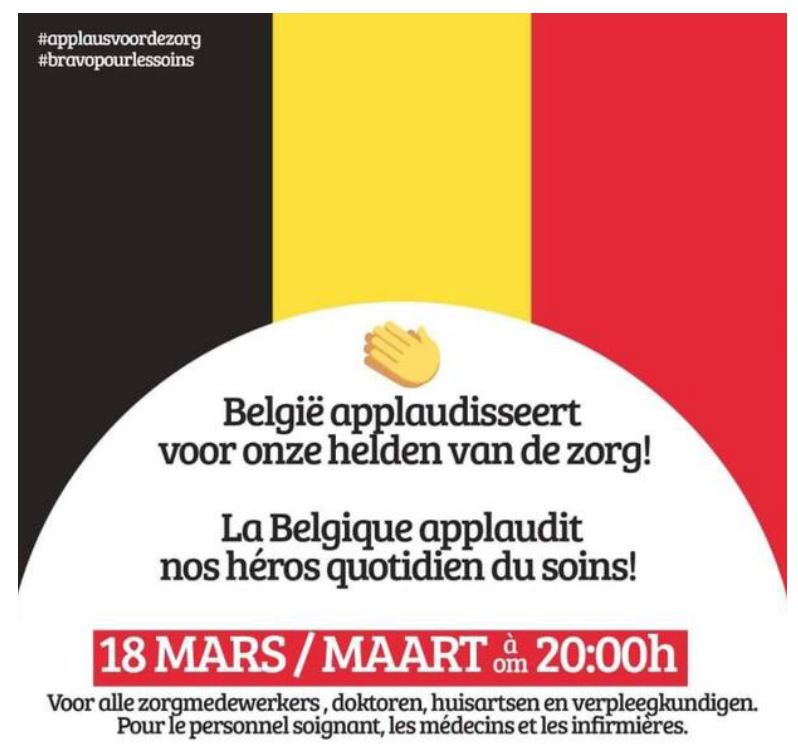

Fuente: Mercredi, applaudissez (2O2O).

que individuos aplaudieran cada tarde-noche desde sus balcones o ventanas a este colectivo, así como las referencias de diversos actores de la esfera pública-medios, políticos, etc.- a él (El personal sanitario, 202O; Lesser, 202O; ONU, 202O), son evidencia de que hay cierta identidad colectiva asumida como unitaria y distinta de otras. Lo mismo ocurre, como veremos más adelante, en aquellos casos en los que individuos enuncian en nombre de este colectivo.

Comencemos por la segmentación. Si bien durante la crisis hubo una serie de colectivos nuevos -los infectados por el coronavirus, los infectados por el virus que se recuperaron, los ancianos infectados que se recuperaron, etc.-, el colectivo de los trabajadores sanitarios no lo es: esta identidad colectiva ya existía en el imaginario de las sociedades antes de la explosión de la pandemia del COVID-19. En cuanto a sus fronteras, la segmentación de esta identidad se da en términos del rubro profesional: el cuidado de la salud humana, especialmente de la salud física. Es este quehacer lo que diferencia a la identidad colectiva de los trabajadores sanitarios de otras, como la de los comerciantes, los políticos y los profesores universitarios, todas ellas categorías sociales que implican postular algo que hace de distintos individuos 
un colectivo. En cuanto a la extensión de esta identidad colectiva, en ella estarían incluidos hombres y mujeres que trabajan como médicos, enfermeros, auxiliares hospitalarios, conductores de ambulancias y todo otro profesional vinculado con la salud. Hasta aquí, por tratarse de una identidad preexistente a la narrativa de la pandemia, no hay nada nuevo.

Para un estudio desde la semiótica, lo interesante comienza con el proceso de actorialización. Si bien este mecanismo asociado a dicha identidad colectiva también existía antes de la explosión de la pandemia, el nuevo contexto dio lugar a nuevas formas de construcción actorial de ella. Antes de la pandemia, la forma de representar a un trabajador sanitario podía pasar por un tipo de vestimenta específico (tapabocas, traje aislante, guantes, túnica blanca) o su asociación con ciertos instrumentos (un estetoscopio colgado del cuello). Pero, durante la pandemia, nuevos mecanismos surgieron para dar vida a esta identidad colectiva; uno de ellos fue la asociación con la idea de que, dentro de la narrativa de la guerra que ha sido empleada de manera hegemónica durante este período (Cassandro, 2020; Testa, 2020), los trabajadores sanitarios han estado "en la primera línea de batalla" (Heroes, 2020; Los sanitarios en primera línea, 2020).

De este modo, a partir de una asociación a otras unidades semánticas existentes en el repertorio cultural, esta identidad colectiva ha visto fortalecido su significado: los trabajadores sanitarios siempre estuvieron en la primera línea en la lucha contra las enfermedades, particularmente aquellas contagiosas, pero es solo ahora, a partir de la asociación reiterada con los soldados y con los (súper)héroes, en un contexto que se siente diferente debido a las restricciones de salir de los hogares, que esta característica, hasta ahora no subrayada de manera enfática, cobra una visibilidad especial, permitiendo una nueva identificación de la identidad colectiva a partir de una propiedad que, en el contexto de una pandemia, se vuelve muy relevante.

Pero hubo, además, otros mecanismos de actorialización de este colectivo, uno de ellos más que interesante desde una perspectiva semiótica y constructivista: las rondas diarias de aplausos por parte de los ciudadanos de distintos países a lo largo y ancho del mundo como forma de reconocimiento al trabajo de este actor social colectivo. Como es sabido, en varios países donde la pandemia ha llegado con fuerza (como Italia, España, Francia, Bélgica y Argentina, por mencionar solo algunos de los tantos en los que se dio este fenómeno), en la primera ola del COVID-19 durante el año 2020 ha habido iniciativas espontáneas de la ciudadanía que generando la tradición de, al finalizar el día (la hora variaba según el país), salir a los balcones o acercarse a las ventanas para, desde el confinamiento, rendir tributo a los trabajadores sanitarios.

Más allá del carácter claramente construido de esta práctica que rápidamente devino en una tradición (aunque fuera temporal), lo que resulta de interés para una 
perspectiva semiótica es la construcción del actor colectivo en tanto receptor invisible de los aplausos. En otras palabras, si los aplausos son concebidos como un acto de enunciación (el aplauso es un modo de producción sígnica que expresa un contenido, por lo general asociado con un mensaje de aprobación, aunque también puede ser ironía), ¿a quiénes están dirigidos los aplausos que se escuchan cada tarde durante los meses de la pandemia? Cuando el ciudadano $C$ en el país $P$ sale a su balcón para aplaudir a los trabajadores sanitarios, ¿en quién piensa?, ¿en algún trabajador que conozca personalmente?, ¿en las representaciones del colectivo que circulan en los medios de comunicación? Semióticamente, en cuanto modo de producción sígnica (Eco, 1976), el aplauso se vuelve un recurso significante, que contribuye a la construcción del actor colectivo: al aplaudir a los trabajadores sanitarios, se vuelve más tangible esta identidad colectiva ya sabida, ya conocida, pero ahora puesta en un pedestal, a partir de un acto también conocido, común y corriente, por lo general asociado a otros contextos no cotidianos (teatros, espectáculos, etc.), como el aplaudir.

En términos de actorialización, durante la pandemia de la COVID-19 hubo también algunas interesantes ocurrencias de autoactorialización, esto es, de puesta en marcha de mecanismos de enunciación por parte de quienes se consideran parte de la identidad colectiva de los trabajadores sanitarios, con el fin de que la visibilidad y unidad del grupo pudiera ser más visibilizada. Ejemplos claros de este tipo fueron rondas de aplausos por parte de los trabajadores sanitarios dedicados a la ciudadanía por quedarse en casa, incluso materiales audiovisuales producidos en diversos hospitales del mundo con mensajes de agradecimiento, como sucedió en la ciudad belga de Lovaina (Hospital staff, 2020). Pero también hubo actos de autoactorialización como forma de tener más fuerza a la hora de transmitir mensajes políticos, por lo general de descontento y disconformidad, como sucedió cuando, en mayo de 2020, la por ese entonces primera ministra de Bélgica, Sophie Wilmès, visitó el Hospital Saint-Pierre de Bruselas y fue recibida por dos líneas de trabajadores sanitarios, en uniformes, dándole la espalda (Hope, 2020; Thomas, 2020). A través de acciones de este tipo, de corte claramente semiótico, distintos individuos autoidentificados como trabajadores sociales contribuyeron no solo a actorializar al actor colectivo, sino también a comunicar en su nombre.

Respecto al mecanismo semiótico de la generalización, es interesante la consideración de cómo ciertos atributos específicos resultantes de la actorialización y, como se discutirá más adelante, de la axiologización, han dado lugar a que ciertas características atribuidas a la identidad colectiva de los trabajadores sanitarios se generalicen como si fueran aplicables a cada uno de sus miembros. Así, durante la pandemia, todos los trabajadores sanitarios pasaron a ser, en términos discursivos e imaginarios, soldados en la primera línea de batalla en la lucha contra el coronavi- 
rus o héroes. Aunque es sabido y evidente que no todos los trabajadores de la salud se encuentran en esta situación de exposición y desgaste (piénsese en el caso, por mencionar un ejemplo, de un oftalmólogo, cuya área de acción a priori no parecería estar relacionada con el coronavirus), estas asociaciones se extienden a todo el colectivo, el que, según el funcionamiento de la generalización, apoyado fuertemente en una necesidad cognitiva de simplificación de la realidad, se ve investido de estas asociaciones. Este fenómeno es sumamente interesante, ya que permite ver la base semiótica de los procesos cognitivos: una vez atribuida una característica genérica a una categoría de sentido (del tipo los trabajadores sanitarios trabajan sin descanso y en condiciones de riesgo para luchar contra el coronavirus), luego cada caso individual que un observador asocie con la categoría de sentido trabajadores colectivos tendrá también, en su articulación cognitiva de la realidad percibida, esas características. Este mecanismo, en definitiva, no dista mucho del que está en juego a la hora de formular estereotipos, por ejemplo, sobre culturas nacionales.

Finalmente, el mecanismo que quizá resulte más interesante desde una perspectiva semiótica es el de la axiologización, ya que claramente se ha puesto en práctica en el caso de los trabajadores sanitarios, que, como vimos, durante la pandemia han sido permanentemente asociados con la figura de héroes (El personal sanitario, 2020; Lesser, 202O; ONU, 202O). Esta asociación se apoya en una comparación de las características relacionadas con los héroes (valentía, sacrificio, coraje, compromiso con lo que es moralmente correcto), que son proyectadas en los trabajadores sanitarios a partir de que su accionar, en tanto identidad colectiva durante la pandemia de la COVID-19, ha reflejado estos principios, en parte porque una de las narrativas dominantes ha sido que el virus es un enemigo, por lo general representado como un villano, con una intencionalidad que va en contra del bienestar de la humanidad (Moreno-Barreneche, 2020a). En España, por mencionar un ejemplo, este actor colectivo recibió, en junio de 2020, el Premio Princesa de Asturias de la Concordia, cuyo jurado ha destacado el "heroico espíritu de sacrificio" de los trabajadores sanitarios, quienes han asumido "graves riesgos y costes personales" (Los sanitarios en primera línea, 2020), en la forma de largas horas de trabajo sin descanso, la cantidad siempre creciente de pacientes, el contacto permanente con la muerte de otros, la falta de equipamiento y condiciones de trabajo adecuados, el riesgo permanente de infección y hasta situaciones de violencia precisamente por ser miembros del colectivo (González-Díaz, 2020).

El heroísmo surge, por lo tanto, a partir de la no claudicación ante circunstancias que fácilmente invitan a hacerlo, lo que se apoya en la idea de un apego a ciertos principios éticos claros. Es así que los trabajadores sanitarios, según afirma el jurado del premio en cuestión, 
con un espíritu de sacrificio personal sobresaliente en favor de la salud pública y del bienestar del conjunto de la sociedad, se han convertido ya en un símbolo de la lucha contra la mayor pandemia global que ha asolado a la humanidad en el último siglo. (Los sanitarios en primera línea, 2020)

Como señala Olga Velásquez (2020) en un editorial publicado en el periódico colombiano La República, "cuando se declara estado de emergencia sanitaria en todo el territorio nacional por causa del covid-19; mágicamente los profesionales, técnicos y tecnólogos de la salud, reaparecieron en el radar mediático como héroes y heroínas sin capa", a lo que agrega que Colombia tiene "como país una gran deuda con los trabajadores de la salud y el gobierno debe volver realidad la política de talento humano para los trabajadores de la salud exigida en las leyes", por lo que propone que "nuestra gratitud debe mostrarse a través de acciones concretas y medibles".

Sin embargo, a pesar de la axiologización positiva que ha dominado las construcciones discursivas asociadas a la pandemia del COVID-19, en muchos casos concretos y particulares ha habido también una axiologización negativa de la identidad colectiva en cuestión, como se ha podido ver en los lamentables casos donde trabajadores sanitarios puntuales han recibido notas anónimas por parte de vecinos, en las que se les pide que dejen sus viviendas de manera temporal por miedo al contagio. La lógica aquí pareciera ser la siguiente: mientras que el individuo I, miembro del colectivo trabajadores sanitarios, es un héroe (axiologización positiva) al que se desea tener cerca cuando se está (o algún ser querido está) infectado con el virus, en tiempos normales es mejor tenerlo lejos, ya que puede ser él la fuente de contagio (axiologización negativa).

Finalmente, parece pertinente señalar el carácter dinámico de estos procesos de construcción identitaria, ya que, una vez pasado el foco de la primera ola de la pandemia del COVID-19, dio la impresión de que los mecanismos descritos en estas páginas se desdibujaran: como afirmaba Bettiza (2020), "alrededor del mundo, los médicos y enfermeras en las primeras líneas están siendo elogiados como héroes por arriesgar sus vidas para tratar a los pacientes. Pero en Italia, ese aprecio se está desvaneciendo". La autora cita a una trabajadora sanitaria, quien declara que "cuando estaban temiendo la muerte, de repente todos nos volvimos héroes, pero ya nos han olvidado". Se puede apreciar cómo, una vez más, el carácter dinámico y procesual de los fenómenos discursivos en el seno de la vida social vuelve a la tarea de capturarlos in vivo un desafío característico del trabajo sociosemiótico. La segunda ola de la pandemia, al menos en Europa, dejó en evidencia este carácter. 


\section{Consideraciones finales}

Como se especificó en la introducción, el objetivo de este artículo fue reflexionar, desde una perspectiva sociosemiótica, sobre los mecanismos a partir de los cuales la identidad colectiva de los trabajadores sanitarios ha sido construida discursivamente en el contexto de la pandemia del COVID-19. Como fue señalado, se trata de una identidad colectiva existente antes de la pandemia que, debido al cambio inesperado y precipitado de circunstancias asociado a la propagación descontrolada del virus, se ve sometida a una serie de procesos de atribución de sentido y significación que la consolidan como categoría de sentido central dentro del relato hegemónico que ha sido utilizado en diversos países para atribuir sentido a la pandemia y a los cambios radicales, tanto a nivel macro como micro, que esta ha traído consigo. Como se argumentó más arriba, las identidades colectivas son artefactos culturales con un rol central en la articulación discursiva de la realidad social, ya que, por el principio de narratividad, ofician como unidades de sentido que permiten articular las distintas tramas que tienen lugar en el campo social, por ejemplo, en la forma de "narrativas de justificación" (Forst, 2017).

Para continuar con el mapeo detallado de los fenómenos discursivos asociados a la pandemia, el próximo paso sería identificar los mecanismos semióticos aquí presentados en corpus textuales concretos y específicamente delimitados, como ser representaciones mediáticas (qué expresiones se utilizan, qué imágenes, qué referencias), creaciones artísticas (caricaturas, grafitis, murales), testimonios de ciudadanos y trabajadores, y otras formas de enunciación que permitirán reconocer los mecanismos de segmentación, actorialización, generalización y axiologización, particularmente aquellos asociados al colectivo de los trabajadores sanitarios. Este trabajo podría organizarse por país, atendiendo de manera comparativa a si las representaciones -y con ellas, la construcción-del colectivo en las respectivas esferas públicas presentan diferencias entre sí. Además, a medida que pase el tiempo y la pandemia se vaya consolidando como un hecho histórico, sería interesante rastrear los cambios diacrónicos en los discursos asociados al colectivo aquí estudiado.

Como se puede apreciar, la semiótica tiene aún mucho material para estudiar minuciosamente y así echar luz sobre los procesos de significación asociados a la pandemia, como forma de clarificar los mecanismos a través de los que los individuos dan sentido a la realidad social. En esta tarea, la disciplina podrá, sin lugar a dudas, contribuir de manera significativa al esclarecimiento de fenómenos discursivos de distintas sociedades y, muy especialmente, a comprender el funcionamiento del fenómeno de la mediatización, tal como fue estudiada por Eliseo Verón. Este artículo ha sido un modesto intento de contribuir a ese fin mayor: en términos 
teóricos, a partir de la presentación de un proceso dinámico de construcción de las identidades colectivas en términos discursivos con base en cuatro mecanismos de naturaleza semiótica; en términos prácticos, mediante el tratamiento de un caso concreto tomado de nuestro presente.

\section{Referencias}

Abdala, Verónica (25 de marzo de 2020). El chino, el cheto, el irresponsable: cuáles son los prejuicios en torno al coronavirus. Clarín. Recuperado de https://www.clarin.com/cultura/ chino-cheto-irresponsable-prejuicios-torno-coronavirus_O_fUEc1rHi-.html

Appiah, Anthony K. (2018). The Lies that Bind. Londres: Profile Books.

Arfuch, Leonor (Ed.), (2005). Identidades, sujetos, subjetividades. Buenos Aires: Prometeo.

Bauman, Zygmunt (2016). Extraños llamando a la puerta. Barcelona: Paidós.

Belga, Par (6 de julio de 2020). Ixelles: inauguration d'une fresque en hommage aux soignants. Nord Eclair. Recuperado de https://nordeclair.sudinfo.be/597037/article/2020-07-06/ ixelles-inauguration-dune-fresque-en-hommage-aux-soignants

Bettiza, Sofia (27 de mayo de 2020). Los médicos italianos que enfrentaron la pandemia: "Fuimos héroes pero ya nos olvidaron". BBC Mundo. Recuperado de https://www.bbc. com/mundo/noticias-internacional-52807958

Cassandro, Daniele (22 de marzo de 2020). Siamo in guerra! Il coronavirus e le sue metafore. Internazionale. Recuperado de https://www.internazionale.it/opinione/danielecassandro/2020/03/22/coronavirus-metafore-guerra

Demaria, Cristina (2006). Semiotica e memoria. Roma: Carocci.

Demuru, Paolo (2017). Praticas de vida. Entre semiótica, comunicação e política. Estudos semióticos, 13(1), 28-39. https://doi.org/10.11606/issn.1980-4016.esse.2017.138409

Dondero, Maria Giulia (2017). Du texte à la pratique: Pour une sémiotique expérimentale. Semiotica, 219, 335-356. https://doi.org/10.1515/sem-2017-0081

Eco, Umberto (1976). Tratado de semiótica general. Barcelona: Lumen.

El personal sanitario encarna el heroísmo contra el coronavirus (15 de abril de 2020). France 24. Recuperado de https://www.france24.com/es/20200415-el-personal-sanitario-encarnael-hero\%C3\%ADsmo-contra-el-coronavirus

Floch, Jean-Marie (1990). Semiótica, marketingy comunicación. Barcelona: Paidós.

Fontanille, Jacques (2008). Pratiques sémiotiques. París: Presses Universitaires de France. 
Fontanille, Jacques (2015). Formes de vie: des jeux de langage à la phénoménologie des cultures. Metodo, 3(1), 21-40.

Forst, Rainer (2017). Normativity and Power: Analyzing Social Orders of Justification. Oxford: Oxford University Press.

Geertz, Clifford (1973). La interpretación de las culturas. Barcelona: Gedisa.

Giannitrapani, Antonello (2013). Introduzione alla semiotica dello spazio. Roma: Carocci.

González-Díaz, Marcos (18 de mayo de 2020). Los violentos ataques al personal de la salud: "No es necesario que nos aplaudan, simplemente que nos respeten". BBC Mundo. Recuperado de https://www.bbc.com/mundo/noticias-america-latina-52710304

Greimas, Algirdas J.; Courtés, Joseph (1979). Sémiotique. Dictionnaire raisonné de la théorie du langage. París: Hachette.

Hénault, Anne (2012). Les enjeux de la sémiotique. París: Presses Universitaires de France.

Heroes of the Front Lines. Stories of the Courageous Workers Risking their Own Lives to Save Ours (2020). Time. Recuperado de: https://time.com/collection/coronavirus-heroes/

Hjelmslev, Louis (1943). Prolegomena to a Theory of Language. Madison: Wisconsin University Press.

Hope, Alan (17 de mayo de 2020). Belgium's Prime Minister gets a chilly reception from hospital staff. The Brussels Times. Recuperado de https://www.brusselstimes.com/all-news/ belgium-all-news/112032/prime-minister-gets-a-chilly-reception-from-hospital-staff/

Hospital staff pay video tribute to Belgian public (27 de junio de 2020). The Brussels Times. Recuperado de https://www.brusselstimes.com/all-news/belgium-all-news/118788/ hospital-staff-pay-video-tribute-to-public/

Laclau, Ernesto (2005). On Populist Reason. Londres: Verso.

Laclau, Ernesto; Mouffe, Chantal (1985). Hegemony and Socialist Strategy. Londres: Verso.

Landowski, Eric (1997). Présences de l'autre. París: Presses Universitaires de France.

Landowski, Eric (2012). ¿Habría que rehacer la semiótica? Contratexto, 20, 127-155.

Landowski, Eric (2014). Sociossemiótica: uma teoria geral do sentido. Galáxia, 27, 10-20. http://dx.doi.org/10.1590/1982-25542014119609

Landowski, Eric (2016a). Interacciones arriesgadas. Lima: Universidad de Lima.

Landowski, Eric (2016b). A prueba del otro. Contratexto, 26, 13-29. https://doi.org/10.26439/ contratexto2016.n026.659 
Lesser, Malen (26 de abril de 2020). Héroes contra el coronavirus: los aplausos son para ellos. La Nación. Recuperado de https://www.lanacion.com.ar/sociedad/heroes-coronavirusaplausos-son-ellos-nid2357040

Los sanitarios en primera línea contra la covid-19, premio Princesa de Asturias de la Concordia (3 de junio de 2020). El País. Recuperado de https://elpais.com/cultura/2020-06-03/ los-sanitarios-en-primera-linea-contra-la-covid-19-premio-princesa-de-asturias-de-laconcordia.html

Manetti, Giovanni (2013). In principio era il segno. Momenti di storia della semiotica nell'antichità classica. Milán: Bompiani.

Marrone, Gianfranco (2013). Figure di città. Spazi urbani e discorsi sociali. Milán: Mimesis.

Marrone, Gianfranco (2018). Prima lezione di semiotica. Bari/Roma: Laterza.

Mazzucchelli, Francesco (2010). Urbicidio. Il senso dei luoghi tra distruzioni e ricostruzioni nella Ex Jugoslavia. Bolonia: Bolonia University Press.

Mercredi, applaudissez nos héros du quotidien (17 de marzo de 2020). La Libre. Recuperado de https://www.lalibre.be/belgique/societe/mercredi-applaudissez-nos-heros-du-quotidien$5 \mathrm{e} 710 \mathrm{f} 3 \mathrm{c} 9978 \mathrm{e} 201 \mathrm{~d} 8 \mathrm{c} 04558$

Moreno-Barreneche, Sebastián (2019). Populism and the Reshaping of the Political Imaginary. Im@go, 14, 37-53. https://doi.org/10.7413/22818138146

Moreno-Barreneche, Sebastián (2020a). From a Biological Entity to a Social Monster. A Semiotic Construction of the Coronavirus during the COVID-19 Pandemic. Fuori Luogo, 7(1), 105-115. https://doi.org/10.6092/2723-9608/7041

Moreno-Barreneche, Sebastián (2020b). Somebody to Blame. On the Construction of the Other in the Context of the COVID-19 Outbreak. Society Register, 4(2), 19-32. https://doi. org/10.14746/sr.2020.4.2.02

Moreno-Barreneche, Sebastián (2020c). Migración y "cultura del miedo": estudio sociosemiótico. Estudios, 43, 65-82. https://doi.org/10.31050/re.vi43.27951

Moreno-Barreneche, Sebastián (2020d). Mind the Gap! On the Discursive Construction of Political Collective Identities. Punctum, 6(2), 11-27.

Mouffe, Chantal (2007). En torno a lo político. Buenos Aires: FCE.

Noor, Poppy (28 de marzo de 2020). 'If I get corona, I get corona': the Americans who wish they'd taken Covid-19 seriously. The Guardian. Recuperado de https://www.theguardian. com/lifeandstyle/2020/mar/28/americans-who-dont-take-coronavirus-seriously

Organización de las Naciones Unidas (2020). Hay que proteger el personal sanitario, héroes que luchan contra el coronavirus. Noticias ONU. Recuperado de https://news.un.org/es/ story/2020/03/1472062 
Pacheco-Miranda, Teresa; Pinto da Costa, Inês (16 de junio de 2020). Eis o mural de Vhils no Hospital de São João. Porque "os profissionais de saúde também precisam de ser cuidados". Público. Recuperado de https://www.publico.pt/2020/06/19/p3/noticia/eis-mural-vhilshospital-sao-joao-profissionais-saude-tambem-precisam-cuidados-1921173

Paolucci, Claudio (2012). Sens et cognition. Signata, 3, 299-316. https://doi.org/10.4000/ signata.948

Testa, Annamaria (30 de marzo de 2020). Smettiamo di dire che è una guerra. Internazionale. Recuperado de https:/www.internazionale.it/opinione/annamaria-testa/2020/03/30/ metafora-guerra-coronavirus

Thomas, Frédéric (21 de mayo de 2020). La visite de Sophie Wilmès à l'hôpital Saint-Pierre: “Une prise d'image". Le Soir. Recuperado de https://plus.lesoir.be/302162/article/2020-05-21/ la-visite-de-sophie-wilmes-lhopital-saint-pierre-une-prise-dimage

Traini, Stefano (2006). Le due vie della semiotica. Teorie strutturali e interpretative. Milán: Bompiani.

Une fresque de street art rend hommage aux soignants, ces super-héros (11 de abril de 2020). Metro. Recuperado de https://fr.metrotime.be/2020/04/11/must-read/une-fresque-destreet-art-rend-hommage-aux-soignants-ces-super-heros/

Velásquez, Olga L. (29 de abril de 2020). ¿Cómo agradecer a los trabajadores de la salud? La República. Recuperado de https://www.larepublica.co/analisis/olga-luciavelasquez-2992704/como-agradecer-a-los-trabajadores-de-la-salud-2999091

Verón, Eliseo (1987). La palabra adversativa. Observaciones sobre la enunciación política. En El discurso político. Lenguajes y acontecimientos (pp.11-26), editado por Eliseo Verón; Leonor Arfuch; María Magdalena Chirico. Buenos Aires: Hachette.

Verón, Eliseo (1988). La semiosis social. Barcelona: Gedisa.

Verón, Eliseo (1989). Semiótica y teoría de la democracia. Revista de Occidente, 92, 130-142.

Verón, Eliseo (1994). Mediatización, comunicación política y mutaciones de la democracia. Revista Semiósfera, 2, 5-36.

Verón, Eliseo (1997). Esquema para el análisis de la mediatización. Diálogos de la comunicación, $48,10-17$.

Verón, Eliseo (1998). Mediatización de lo político. En Comunicación y política (pp. 220-236), compilado por Gilles Gauthier; André Gosselin; Jean Mouchon. Barcelona: Gedisa.

Violi, Patrizia (2014). Paesaggi della memoria. Milán: Bompiani.

Violi, Patrizia (2017). Due vie per la semiotica o un incrocio di sguardi? Algirdas Greimas e Umberto Eco a confronto. Entornos, 30(1), 25-33. https://doi.org/10.25054/01247905.1420 